\title{
A Rapid and Accurate Method for Estimating Tomato Lycopene Content by Measuring Chromaticity Values of Fruit Purée
}

\author{
Joshua R. Hyman', Jessica Gaus ${ }^{2}$, and Majid R. Foolad ${ }^{3}$ \\ Department of Horticulture and The Intercollege Graduate Degree Program in Genetics, 217 Tyson \\ Building, The Pennsylvania State University, University Park, PA 16802
}

\begin{abstract}
ADDITIONAL INDEX WORDS. Lycopersicon esculentum, Lycopersicon pimpinellifolium, carotenoids, $\beta$-carotene, colorimetry, fruit color, nutritional quality, HPLC

ABstract. Lycopene is the red pigment and a major carotenoid in tomato (Lycopersicon esculentum Mill.) fruit. It is a potent natural antioxidant, and the focus of many tomato genetics and breeding programs. Crop improvement for increased fruit lycopene content requires a rapid and accurate method of lycopene quantification. Among the various available techniques, high-performance liquid chromatography (HPLC) can be accurate, however, it is laborious and requires skilled labor and the use of highly toxic solvents. Similarly, spectrophotometric methods, although easier than HPLC, also require time-consuming extractions and may not be as accurate as HPLC, as they often overestimate fruit lycopene content. Colorimetric estimation of fruit lycopene using chromaticity values has been proposed as an alternative rapid method. Previous studies that examined the utility of this technique, however, were confined to the evaluation of only one or few cultivars and, therefore, lacked broad applicability. The purpose of the present study was to examine the utility of chromaticity values for estimating lycopene and $\beta$-carotene contents in tomato across diverse genetic backgrounds. Measurements of the chromaticity values $\left(L^{*}, a^{*}, b^{*}, C^{*}, h^{*}\right)$ were taken on whole fruit and purée of 24 tomato genotypes and were compared with HPLC measurements of fruit lycopene and $\beta$-carotene. Examination of different regression models indicated that a model based on the transformed value $a^{* 4}$ from purée measurements explained up to $94.5 \%$ of the total variation in fruit lycopene content as measured by HPLC. When this model was applied to a second set of fruit harvested at a later date from the same 24 genotypes, it explained more than $90 \%$ of the total variation in lycopene, suggesting its reliability. The best estimation for $\beta$-carotene content was obtained by using the $b^{*}$ chromaticity value from whole fruit measurements or the transformed $a^{* 2}$ value from purée measurements. Neither model, however, could explain more than $55 \%$ of the variation in $\beta$-carotene content, suggesting that chromaticity values may not be appropriate for estimating tomato $\beta$-carotene content. The overall results indicated that fruit lycopene content could be measured simply and rather accurately across a wide range of tomato genotypes using chromaticity values taken on fruit purée.
\end{abstract}

As the effects of food ingredients on human health have become more recognized, the emphasis on breeding for nutritional components has increased. Abeneficial component in tomato fruit that recently has garnered great public attention is the carotenoid lycopene. It is the red pigment in tomato and a strong antioxidant, and a precursor to the production of $\alpha$-carotene and $\beta$-carotene. The antioxidant capacity of lycopene is at least twice that of $\beta$-carotene (Di Mascio et al., 1990; Levy et al., 1995; Sies and Stahl, 1998). Fresh tomatoes and tomato products are the major sources of lycopene in the United States diet (Beecher, 1998; Chug-Ahuja et al., 1993; Rao et al., 1998). Previous research has indicated that consumption of lycopene is associated with

Received for publication 8 Aug. 2003. Accepted for publication 3 May 2004. Contribution 438 of the Dept. of Horticulture, The Pennsylvania State Univ. This paper is a portion of a thesis submitted by Joshua R. Hyman in partial fulfillment of the requirements for the Degree of Doctor of Philosophy at The Pennsylvania State Univ.. Financial support from the Agricultural Research Funds administered by the Pennsylvania Dept. of Agriculture (\#ME400494), the Pennsylvania Vegetable Marketing and Research Program, and the College of Agricultural Sciences, the Pennsylvania State Univ. is appreciated. We thank Charles Heuser, James Sellmer, Arun Sharma, and Shazia Husain for reviewing the manuscript before submission. We also thank the technical support of Rick Grazzini, Ralph Muma, Liping Zhang, and Guoyang Lin.

'Postdoctoral Associate; current address: USDA-ARS, Vegetable Crops Research Unit, Dept. of Horticulture, Univ. of Wisconsin-Madison, Madison, WI 53706. ${ }^{2}$ Research Assistant; current address: Horticultural Science Dept., Box 7609, North Carolina State Univ., Raleigh, NC 27695.

${ }^{3}$ Professor and corresponding author: e-mail mrf5@psu.edu. reduced incidence of certain cancers such as prostate, mouth, and colon (Giovannucci, 1999) and with lower risk of myocardial infarction (heart attack) and cataracts (Kohlmeier et al., 1997). Although the mechanism(s) by which lycopene exerts its effects is not completely known, its health benefits are thought to be due to the ability to quench free radicals (Bertram and Zhang, 1994; Gerster, 1997; Krinsky, 1998); induce cell to cell communication (Zhang et al., 1991, 1993); and modulate hormonal, immune systems, and other metabolic pathways (Fuhramn et al., 1997; Rao and Agarwal, 1998). However, regardless of its mechanism of action, enhancing fruit lycopene content by genetic means has become an important goal for many tomato breeding programs worldwide. Genetic improvement of fruit lycopene content is particularly important in processing tomatoes, as lycopene is more readily absorbed in the human body in its processed forms as compared to its raw form in fresh tomatoes (Gartner et al., 1997; Stahl and Sies, 1996).

Development of tomato cultivars with improved fruit lycopene content using traditional breeding approaches requires an efficient screening method. Adifficulty in screening tomato populations for fruit lycopene and other carotenoids has been the quantification of their concentrations in the fruit (Chen et al., 1999). Chemical measurement of carotenoids can be accomplished by high-performance liquid chromatography (HPLC) (Emenhiser et al., 1995; Hart and Scott, 1995; Scott et al., 1996) or spectrophotometric methods using fruit extracts (Fish et al., 2002; Sadler et al., 1990). 
Although HPLC analysis allows accurate quantification of individual pigments and separation of isomers, it is a very laborious process and requires a high level of skill to produce consistent results (Kimura and Rodriguez-Amaya, 1999). Furthermore, the chemicals used in extraction of carotenoids and their elution on chromatographic columns pose hazards to the experimenter and the environment. Similarly, the spectrophotometric method requires time-consuming extractions, and may not be as accurate as HPLC as it often overestimates the concentration of lycopene (Fish et al., 2002; Rao et al., 1998). Thus, researchers have been seeking alternative approaches to measuring fruit carotenoids content more efficiently.

Various techniques have been employed and compared for their efficiency and accuracy for measuring tomato fruit lycopene content. Both the colorimetric method, using chromaticity values (Arias et al., 2000; D'Souza et al., 1992), and the spectrophotometric method, using either fruit extracts (Rao et al., 1998) or purée (Davis et al., 2003), have been described as being less time consuming or less destructive than HPLC. However, the previous methods and the derived regression models may have limited applicability. For example, previous colorimetric studies were based on the use of only three (D'Souza et al., 1992) or one cultivar (Arias et al., 2000), and the variation in fruit lycopene content, and thus the derived regression models for estimating lycopene were based mainly on measurements taken at different stages of fruit ripening. In these studies, although correlations between the chromaticity values and HPLC measurements (Arias et al., 2000) or spectrophotometric quantification of lycopene (D'Souza et al., 1992) were generally high for individual genotypes, the applicability of the proposed regression models to a broad range of genotypes was not determined. Also, the spectrophotometric method reported by Rao et al. (1998), although it required less time than HPLC and resulted in lycopene quantifications that were comparable to measurements taken by HPLC (on average differing by $11 \%$ ), was still much more time-consuming than colorimeter measurements because it required chemical extractions. Furthermore, the extraction-free "purée absorbance method" proposed by Davis et al. (2003), although simple and rapid, compared the lycopene estimates with quantifications made by using regular spectrophotometric method. Because spectrophotometric methods generally are not as accurate as HPLC in quantifying different types of carotenoids, the accuracy of Davis et al.'s (2003) method in estimating the true quantity of the fruit lycopene content is unknown (see Discussion for more detail). The purpose of the present study was to determine whether a procedure based on simple colorimeter measurements could yield estimates of lycopene content with comparable accuracy as methods requiring chemical extractions, and if the method can be applicable to a broad range of tomato genotypes.

\section{Materials and Methods}

Plant materials. Twenty-four genotypes, including a broad range of tomato cultivars and breeding lines, several accessions of the related wild species L. pimpinellifolium (Jusl.) Mill., and three interspecific $F_{1}$ hybrids, were used (Table 1). Plants were grown under standard greenhouse conditions for tomato and at maturity fruit were harvested from all plants on two dates, $12 \mathrm{Mar}$. and 19 Mar. 2001. The L. pimpinellifolium accessions LA2336 and PI163245 were yellow-fruited, whereas all other genotypes were red-fruited. Across genotypes, individual fruit weight ranged from 1.5 to $150.1 \mathrm{~g}$ (Table 1$)$.
Colorimetric measurements. At each harvesting date, one to five fruit (depending on the availability) of each accession were harvested and used to measure chromaticity values $\mathrm{L}^{*}$, $\mathrm{a}^{*}, \mathrm{~b}^{*}, \mathrm{C}^{*}$, and $\mathrm{h}^{*}$ (Commission Internationale de'Eclairage) (Hunter and Harold, 1987), using a Minolta spectrophotometer Model CM 3500d (Minolta, Ramsey, N.J.). The L* value is a measurement of the lightness or the amount of light reflected. The $\mathrm{a}^{*}$ value indicates the intensity of the red (+ values) or green ( - values) coloration, while the $\mathrm{b}^{*}$ value indicates the intensity of the yellow (+ values) or blue (- values) coloration. The $\mathrm{C}^{*}$ and $h^{*}$ values are measures of the chroma $\left(\sqrt{a^{* 2}+b^{* 2}}\right)$ and hue angle $\left(\tan ^{-1} \mathrm{~b}^{*} / \mathrm{a}^{*}\right)$, respectively.

Colorimetric measurements were made on both whole fruit and purée. For whole fruit, measurements were made on one to five fruit of each accession (in each harvest), depending on the availability of fruit. Also, depending on fruit size, up to 10 readings per fruit were taken, which were averaged to obtain reliable estimates of chromaticity values for each fruit. When more than one fruit was used for whole fruit measurements, the chromaticity values were weighted by the size of the fruit. To compare whole fruit values to their resulting purée values, the average chromaticity value for each fruit was multiplied by its weight. The size-adjusted chromaticity values for all fruits of an accession were summed and divided by the total weight of all fruits of that accession. To produce purée, all fruits of each accession were placed in either a $500-\mathrm{mL}$ beaker or a $50-\mathrm{mL}$ polypropylene centrifuge tube (depending on fruit size), $0.1 \%$ (w/w) butylated hydroxytoluene (BHT) was added as an antioxidant, and the fruit were ground using a Polytron (Brinkman Instruments, Westbury, N.Y.) until all fragments of skin were reduced to $<1 \mathrm{~mm}$ in width. Two 1-g purée samples were taken for HPLC analysis and the remaining was used for spectrophotometric measurements of the chromaticity values. Five independent spectrophotometric readings were taken on purée of each accession. The purée readings were taken through a thin layer of plastic film (Borden SealWrap, PVC film; AEP Industries, South Hackensack, N.J.) to protect the spectrophotometer, with the purée being thoroughly mixed by continuous stirring in between sample readings. Chromaticity values were then adjusted for any potential distortion caused by the plastic film. The adjustment coefficient was determined in a separate experiment by taking multiple colorimeter readings on whole fruits with and without plastic and using regression analysis. Adjusted chromaticity values for purée were used in all further analyses.

HPLC MEASUREMENTS. Extractions. A volume of $10 \mathrm{~mL}$ of extraction solvent, 1 methanol: 1 tetrahydrofuran (THF), was added to $1 \mathrm{~g}$ of purée in a glass centrifuge tube. The extraction solvent contained $0.1 \%$ BHT as an antioxidant to prevent degradation of the carotenoids (Scott, 1992). Samples remained in the extraction solvent at room temperature until further processing, but never for more than $18 \mathrm{~h}$. The purée and supernatant containing the carotenoids were then poured into a Buchner funnel and filtered through a $1.6-\mu \mathrm{m} \mathrm{GF} / \mathrm{A}$ filter (Whatman, Clifton, N.J.) into a glass Erlenmeyer flask. The purée on the filter was rinsed repeatedly with solvent, never allowing it to dry out. When the purée was almost colorless, it was transferred back into the glass centrifuge tube and suspended in 4-5 $\mathrm{mL}$ of solvent for approximately 1 min. The supernatant was poured through the filter and the purée re-suspended in solvent. This was repeated two to three times or until no color was detectable in the solvent.

To remove any polar carotenoids, the supernatant was washed with $2 \times$ volume of $10 \% \mathrm{NaCl}(\mathrm{w} / \mathrm{v})$ in a separatory funnel. Ten 
Table 1. Fruit weight, lycopene and $\beta$-carotene content as measured by HPLC, and $\beta$-carotene content as a percentage of both carotenoids in tomato genotypes used in this study.

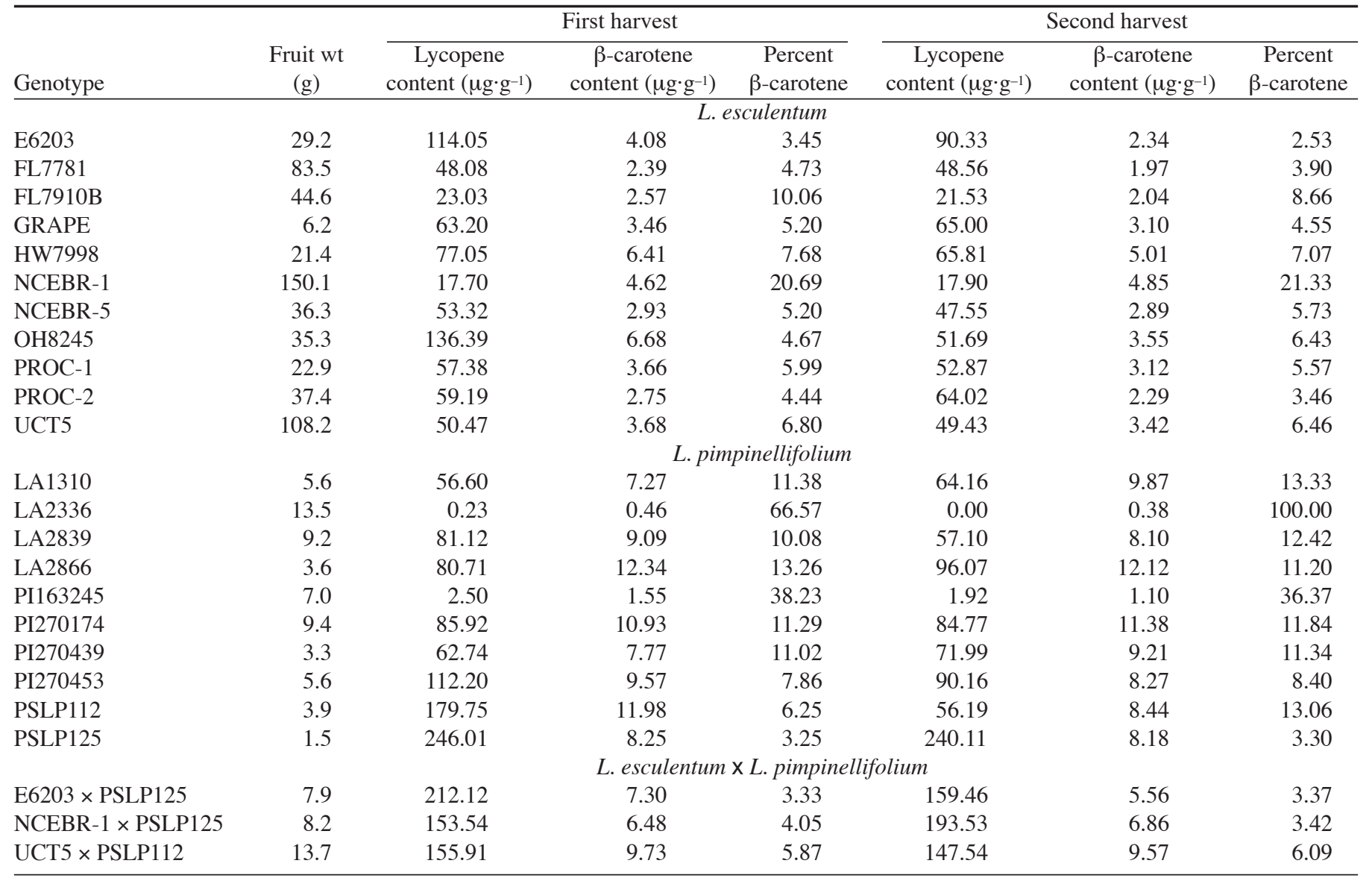

milliliters of dichloromethane (DCM) was added, the separatory funnel was inverted and the stopcock opened to de-gas. The solution was agitated for $30 \mathrm{~s}$ and allowed to separate for $15 \mathrm{~min}$. If clear phase separation did not occur due to excessive methanol or THF, additional DCM and/or saltwater was added and agitation was repeated. The denser organic phase containing the non-polar carotenoids was collected leaving the polar carotenoids and chlorophyll in the aqueous phase. An additional 10 $\mathrm{mL}$ of DCM was added to the aqueous phase and a second round of agitation and separation was performed to collect any residual nonpolar carotenoids. The organic phase was collected again and the aqueous phase (containing polar carotenoids) was discarded. The organic phase was transferred back into the separatory funnel and washed with $2 \times$ volume of fresh saltwater solution to remove any remaining polar carotenoids. This also reduced the amount of methanol and residual water in the organic phase.

The washed samples were then dried under nitrogen to almost complete dryness. The extracts were re-suspended in $4 \mathrm{~mL}$ of THF containing $0.1 \%$ BHT and stored at $-20^{\circ} \mathrm{C}$. HPLC measurements were taken within $3 \mathrm{~d}$.

Chromatographic Conditions. Carotenoids were separated on a Vydac 201 TP54 $(250 \times 4.6 \mathrm{~mm}, 5 \mathrm{~mm}$ particle size $)$ reversed phase $\mathrm{C}_{18}$ analytical column (The Separations Group, Hesperia, Calif.) coupled with a Nova-Pak $\mathrm{C}_{18}$ Guard-Pak guard column (4 mm particle size) containing a $2-\mu \mathrm{m}$ filter (Waters Corp., Milford, Mass.). An isocratic mobile phase of 9 methanol : 1 THF (Epler et al., 1992) containing $0.1 \% N, N$-di-isopropylethylamine (F. Khachik, personal communication) was used to separate carot- enoids (Kamber and Pfander, 1984). The mobile phase was filtered through a $0.2-\mu \mathrm{m}$ nylon filter and de-gassed with helium. Light absorption was measured with a Waters 996 photodiode array detector (Waters Corp.) scanning from 350 to $550 \mathrm{~nm}$.

Carotenoid quantification. Lycopene and $\beta$-carotene were quantified using external standards suspended in THF and injected every tenth sample. No absorption data existed for these carotenoids in THF, so it was necessary to estimate the absorption coefficients (i.e., the theoretical absorbance of a $1 \%$ solution in a 1-cm path) in THF from standards quantified using published absorption coefficients in light petroleum or petroleum ether (PE). For each carotenoid, 10 identical dilutions were made, five in PE and five in THF. Three sets of readings were taken of each dilution in a Spectronic 1001 multi-wavelength spectrophotometer (Milton Roy Co., Rochester, N.Y.). Peak readings for lycopene were taken at 468 and $470 \mathrm{~nm}$ in PE and 478 and $480 \mathrm{~nm}$ in THF. Peak readings for $\beta$-carotene were taken at 448 and $449 \mathrm{~nm}$ in $\mathrm{PE}$ and 458 and $459 \mathrm{~nm}$ in THF. A bathochromic shift occurred in THF, increasing the peak wavelength by $\approx 9.6 \mathrm{~nm}$ for lycopene and $10.0 \mathrm{~nm}$ for $\beta$-carotene. An absorption coefficient of 3450 at a peak wavelength of $470 \mathrm{~nm}$ was used to quantify the lycopene in PE (Britton et al., 1995), which, based on the assumption that the average concentration was the same in THF, yielded an absorption coefficient of 3255 for lycopene in THF at a wavelength of $480 \mathrm{~nm}$. An absorption coefficient of 2592 at a peak wavelength of $449 \mathrm{~nm}$ was used to quantify the $\beta$-carotene in PE (Britton et al., 1995), which yielded an absorption coefficient of 2400 for $\beta$-carotene in THF at a peak wavelength of $459 \mathrm{~nm}$. Working 
standards of lycopene and $\beta$-carotene in THF were quantified using these estimates and combined to produce a single working standard containing both carotenoids.

Lycopene standards were tested for linearity of response in a spectrophotometer and on the HPLC system. A series of five dilutions were made of the lycopene standard in the mobile phase to yield concentrations of $8,16,24,32$, and $40 \mu \mathrm{g} \cdot \mathrm{mL}^{-1}$. Aliquots were taken of all five of these for spectrophotometric analysis. With the exception of the lowest concentration, all were diluted 1:4 with the mobile phase and their absorption was measured at $469 \mathrm{~nm}$ on a Beckman DU 650 scanning spectrophotometer (Beckman Coulter, Fullerton, Calif.). The five original dilutions were run on the HPLC system described and the absorption measured as the area under the chromatogram at $471.7 \mathrm{~nm}$. Both the spectrophotometer and HPLC readings showed a linear response over the range tested. This range equates to a range of 32 to 160 $\mu \mathrm{g} \cdot \mathrm{g}^{-1}$ for the samples tested as they were extracts of 1 -g samples suspended in $4 \mathrm{~mL}$ of injection solvent.

DATA ANALYSIS. HPLC measurements of each carotenoid were compared graphically and statistically against purée and whole fruit chromaticity values $\mathrm{L}^{*}, \mathrm{a}^{*}, \mathrm{~b}^{*}, \mathrm{C}^{*}$ and $\mathrm{h}^{*}$ as well as various functions of these values. Chromaticity values of all samples were plotted against the HPLC measurements and assessed visually for linear relationships. For those relationships that appeared to be non-linear, a series of logarithmic and exponential transformations were assessed for linearity. Transformations included the natural $\log$ of the values as well as the first through fifth power of the values. HPLC estimates of carotenoids were then regressed against transformed chromaticity values, and regression models with the highest predictive power, measured as the coefficient of determination, $R^{2}$ value, were identified. Transformations with the greatest predictive power were then incremented or decremented by tenths of a power until no better fit could be identified.

Predictive regression models were developed and tested using data collected on fruits from the two harvests. Based on data collected from the first harvest, models were developed to predict HPLC estimates of lycopene or $\beta$-carotene content using chromaticity values. The models were then tested against the data collected from the second harvest to assess their accuracy as well as their ability to estimate fruit carotenoid content. Accuracy was measured as the average deviation of the model from the carotenoid measurements by HPLC in the second harvest. The ability of the model to explain relative carotenoid content was measured as the coefficient of determination, $R^{2}$ value, of the model with the second set of data. Models were also compared to a model reported in a previous study (D'Souza et al., 1992), that is Lycopene $=5.6+71.2\left(\mathrm{a}^{*} / \mathrm{b}^{*}\right)^{2}$, for estimating fruit lycopene contents based on tomato skin disks of three cultivars analyzed at different stages of fruit maturity.

\section{Results}

Lycopene was the primary carotenoid in all but the two yellow-fruited accessions, and its concentration was more variable across genotypes than was $\beta$-carotene concentration. Fruit lycopene content ranged from 0 to $246 \mu \mathrm{g} \cdot \mathrm{g}^{-1}$ fresh weight $(\mathrm{FW})$, whereas $\beta$-carotene content ranged from $<1$ to $12 \mu \mathrm{g} \cdot \mathrm{g}^{-1} \mathrm{FW}$ across the 24 tomato genotypes (Table 1 ). $\beta$-carotene tended to increase with increasing lycopene content, but not to the same degree. This resulted in a significant positive correlation between lycopene and $\beta$-carotene content in both the first $(r=0.60, P<$ $0.01)$ and the second harvest $(r=0.49, P<0.05)$ and a significant negative correlation between lycopene content and $\beta$-carotene as a percentage of total carotenoids in both harvests, $r=-0.52$ and $-0.44(P<0.05)$, respectively.

Percent $\beta$-carotene was very stable for all accessions in the two harvests, with a correlation of $0.98(P<0.01)$ between the first and the second harvest. For 21 red-fruited accessions, $\beta$-carotene accounted for $2.5 \%$ to $13.5 \%$ of the total carotenoids, whereas in the two yellow-fruited accessions (LA2336 and PI163245, with very low lycopene contents) and in the red-fruited breeding line NCEBR-1 there were much higher percentages of $\beta$-carotene (Table 1).

LyCOPENE ESTIMATION. Visual inspection of scatter plots of the data from the first harvest indicated that not all relationships between lycopene measurements by HPLC and chromaticity values $\mathrm{L}^{*}, \mathrm{a}^{*}, \mathrm{~b}^{*}, \mathrm{C}^{*}$, and $\mathrm{h}^{*}$ were linear. However, transformation of chromaticity values resulted in more linear relationships. For example, transformation of $\mathrm{a}^{*}$ and $\mathrm{a}^{*} / \mathrm{b}^{*}$ values from purée colorimeter measurements to $\mathrm{a}^{* 4}$ and $\left(\mathrm{a}^{*} / \mathrm{b}^{*}\right)^{2.5}$ and transformation of $h^{*}$ and $a^{*} / b^{*}$ values from whole fruit colorimeter measurements to $\sqrt{h^{*}}$ and $\left(\mathrm{a}^{*} / \mathrm{b}^{*}\right)^{2.5}$, respectively, yielded the best fit linear models (Table 2, Fig. 1). The most notable improvement, however, was when purée $\mathrm{a}^{*}$ value was transformed to $\mathrm{a}^{* 4}$.

Selection of a chromaticity parameter with the best predictive power to estimate lycopene content (as measured by HPLC) was dependent upon whether the colorimetric measurements were taken on purée or on whole fruit. Based on the data from the first harvest, $R^{2}$ value was the highest (74\%) on whole fruit when $\left(a^{*} / b^{*}\right)^{2.5}$ values were used to estimate lycopene (Table 2 , Fig. 1b). The a* value, which had very little predictive value when measurements were taken on whole fruit $\left(R^{2}=31 \%\right)$, had the second highest $R^{2}$ value $(74 \%)$ when measurements were taken on purée. Furthermore, after transformation, the purée $\mathrm{a}^{* 4}$ value was by far the best predictor of lycopene content with an $R^{2}$ value of $94.5 \%$ (Table 2, Fig. 1a). Also, the predictive power of the model based on purée a*4 value did not change significantly when the two yellow-fruited accessions were excluded, only reducing the $R^{2}$ value to $93.4 \%$.

When using the chromaticity values $\mathrm{a}^{*}, \mathrm{a}^{* 2}$, or $\mathrm{a}^{* 4}, R^{2}$ values increased substantially when lycopene estimates and the derived regression models were based on the purée colorimeter readings (Table 2). For example, variation in the transformed chromaticity value $\mathrm{a}^{* 4}$ explained $90.1 \%$ of the variation in actual lycopene content (as measured by HPLC) in the second harvest. In fact, $\mathrm{a}^{* 4}$ value was even a better predictor of lycopene content of each accession in the second harvest than was the lycopene measurements by HPLC of the same accessions in the first harvest. For example, variation in lycopene content measured by HPLC on matched accessions in the first harvest explained only $72.9 \%$ of the variation in lycopene content of the second harvest. It appeared that measurements of the purée $a^{* 4}$ values compensated not only for differences between accessions but also for potential differences in stages of ripening of each accession.

The whole fruit model presented here based on $\left(\mathrm{a}^{*} / \mathrm{b}^{*}\right)^{2.5}$ values was as good as the model reported by D'Souza et al. (1992), which was based on $\left(\mathrm{a}^{*} / \mathrm{b}^{*}\right)^{2}$ values taken on skin disks from whole fruit, for explaining the variation in fruit lycopene content from the second harvest. While our model explained $69.8 \%$ of the variation in lycopene content in the second harvest, their model explained $68.4 \%$. However, lycopene estimates from the purée model developed here were systematically less biased than estimates from any of the previously reported models, as described below. 
Table 2. Coefficient of determination $\left(R^{2}\right)$ for selected regression models relating chromaticity values taken on tomato purée and whole fruit with lycopene and $\beta$-carotene contents as measured by HPLC. All correlations are significant at $P<0.05$ unless otherwise noted as nonsignificant (NS).

\begin{tabular}{|c|c|c|c|c|c|c|c|c|}
\hline \multirow{2}{*}{$\begin{array}{l}\text { Chromaticity } \\
\text { value }\end{array}$} & \multicolumn{4}{|c|}{ Lycopene } & \multicolumn{4}{|c|}{$\beta$-carotene } \\
\hline & Purée & & Whole fru & & Purée & & Whole fru & \\
\hline$\overline{\mathrm{L} *}$ & 0.228 & & 0.293 & & 0.070 & NS & 0.413 & \\
\hline$a^{*}$ & 0.741 & & 0.310 & & 0.531 & & 0.010 & NS \\
\hline$a^{* 2}$ & 0.865 & & 0.295 & & 0.542 & & 0.001 & NS \\
\hline$a^{* 4}$ & 0.945 & & 0.235 & & 0.468 & & 0.001 & NS \\
\hline$b^{*}$ & 0.002 & NS & 0.286 & & 0.085 & NS & 0.551 & \\
\hline $\mathrm{C}^{*}$ & 0.564 & & 0.021 & NS & 0.545 & & 0.394 & \\
\hline $\mathrm{h}^{*}$ & 0.419 & & 0.531 & & 0.211 & & 0.422 & \\
\hline$\sqrt{\mathrm{h}^{*}}$ & 0.440 & & 0.576 & & 0.203 & & 0.433 & \\
\hline$a * / b *$ & 0.491 & & 0.654 & & 0.178 & & 0.433 & \\
\hline$(\mathrm{a} * / \mathrm{b} *)^{2}$ & 0.545 & & 0.729 & & 0.127 & & 0.389 & \\
\hline$(\mathrm{a} * / \mathrm{b} *)^{2.5}$ & 0.551 & & 0.736 & & 0.106 & NS & 0.355 & \\
\hline
\end{tabular}
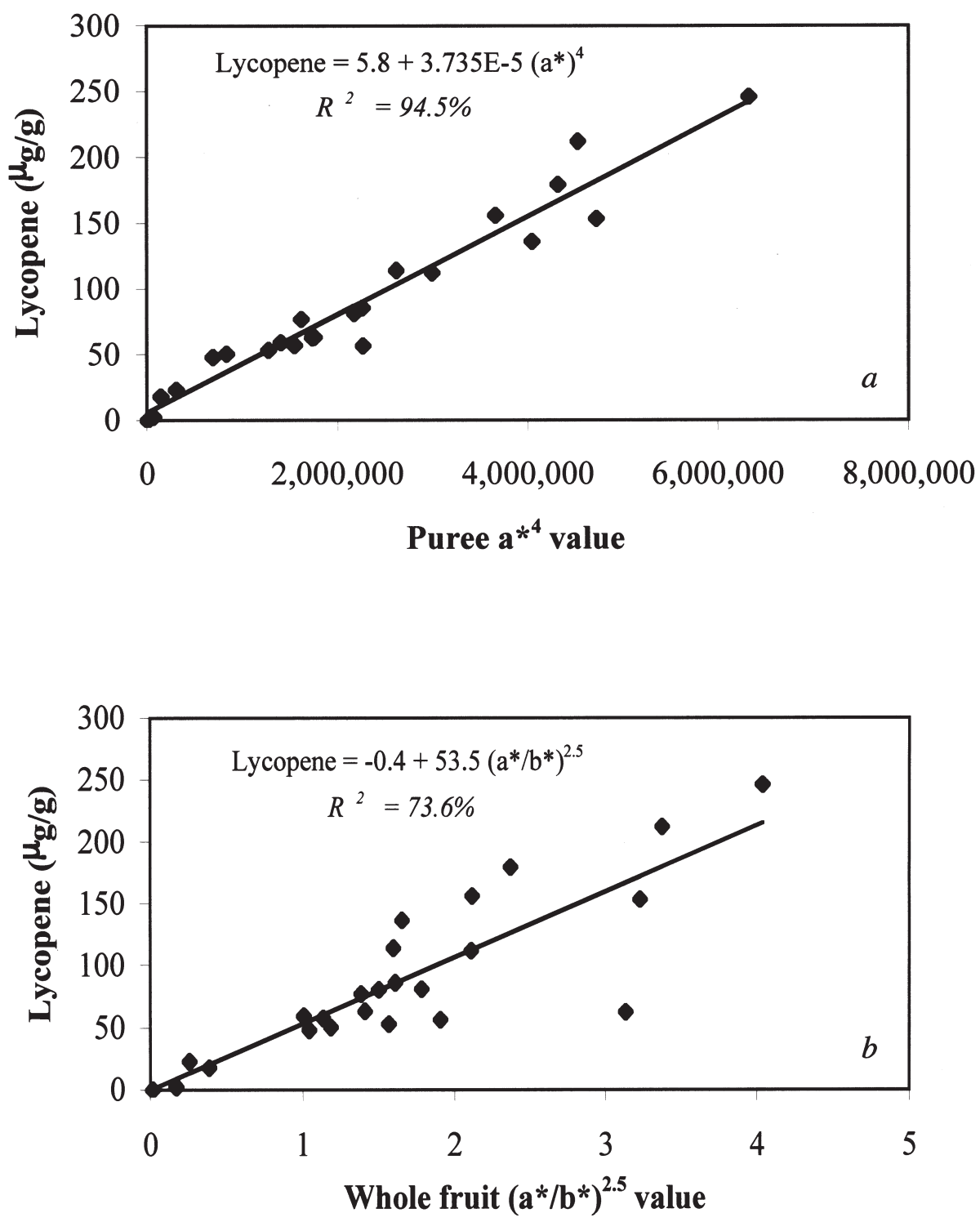

Fig. 1. Relationships sbetween lycopene content measured by HPLC and either the transformed chromaticity $\mathrm{a}^{* 4}$ value measured by colorimeter on tomato purée $(\mathrm{a})$ or the transformed $\left(\mathrm{a}^{*} / \mathrm{b}^{*}\right)^{2.5}$ value measured by colorimeter on whole tomato (b). Data are from the first harvest.
Generally, all models tended to overestimate the lycopene content relative to HPLC measurements, however, the overestimation was rather less by the purée model presented here. When applied to the data from the second harvest, the purée model, Lycopene $=5.8+3.735 \times 10^{-5} \mathrm{a}^{4}$, produced lycopene estimates that were on average $1 \mu \mathrm{g} \cdot \mathrm{g}^{-1} \mathrm{FW}$ greater than the HPLC estimates, with an average error of $13 \mu \mathrm{g} \cdot \mathrm{g}{ }^{-1} \mathrm{FW}$. Estimates of lycopene using the whole fruit model, Lycopene $=-0.4+53.5\left(\mathrm{a}^{*} / \mathrm{b}^{*}\right)^{2.5}$, were on average $14 \mu \mathrm{g} \cdot \mathrm{g}^{-1} \mathrm{FW}$ greater than the HPLC estimates, with an average error of $23 \mu \mathrm{g} \cdot \mathrm{g}^{-1}$ FW. In comparison, the model by D'Souza et al. (1992) overestimated lycopene content by an average of $34 \mu \mathrm{g} \cdot \mathrm{g}^{-1} \mathrm{FW}$, with an average error of $38 \mu \mathrm{g} \cdot \mathrm{g}^{-1} \mathrm{FW}$. Similarly, the results reported by Rao et al. (1998) indicated that their spectrophotometric methods overestimated fruit lycopene content by an average of $16.5 \mu \mathrm{g} \cdot \mathrm{g}^{-1} \mathrm{FW}$, compared to HPLC measurements of lycopene, even though the carotenoids underwent extensive extractions and quantifications against standards. Furthermore, the accuracy of the "purée absorbance method" proposed by Davis et al. (2003) could not be readily determined as they compared estimates of lycopene contents with only quantifications made by a spectrophotometric method and not HPLC measurements. Previous studies had indicated that quantifications of lycopene by spectrophotometric methods were on average different from HPLC measurements by about $11 \%$ (Rao et al., 1998).

$\beta$-CAROTENE ESTIMATION. Visual inspection of the data from the first harvest indicated that some of the relationships between $\beta$-carotene measurements by HPLC and chromaticity values could be made more linear through transformation. For example, the transformation of the $a^{*}$ values from purée measurements and $\mathrm{h}^{*}$ values from whole fruit measurements to $\mathrm{a}^{* 2}$ and $\sqrt{\mathrm{h}^{*}}$, respectively, yielded better fits for these chromaticity parameters. However, unlike the transformation of the $\mathrm{a}^{*}$ puree value to $\mathrm{a}^{* 4}$ as a predictor for lycopene content, neither $\mathrm{a}^{* 2}$ nor $\sqrt{\mathrm{h}^{*}}$ transformation resulted in a substantial gain in the $R^{2}$ for estimation of $\beta$-carotene content (Table 2).

Similar to that for lycopene, selection of the best regression model to estimate $\beta$-carotene content from chromaticity values was dependent on whether colorimeter measurements were taken on purée or whole fruit. The $\mathrm{a}^{* 2}$ value and $\mathrm{C}^{*}$ value from purée measurements were equally good but neither relationship was particularly strong. Regressing $\beta$-carotene content on these parameters yielded the equations $\beta$-carotene $=$ 
$0.9+0.00365 \mathrm{a}^{* 2}\left(R^{2}=54.1 \%\right)$ and $\beta$-carotene $=-11.4+0.305$ C* $\left(R^{2}=54.4 \%\right)$, respectively (Table 2$)$. Regressing $\beta$-carotene content on the $\mathrm{b}^{*}$ value from whole fruit measurements resulted in the equation $\beta$-carotene $=13.4-0.305 \mathrm{~b}^{*}\left(R^{2}=55.1 \%\right)$. The negative regression coefficient indicated that the less yellow the fruit was, the more $\beta$-carotene was present. Furthermore, unlike that for estimating lycopene, when estimating $\beta$-carotene from chromaticity values, there was no benefit in using purée as compared to whole fruit (Table 2).

Generally, higher correlations were observed between chromaticity values and lycopene content (as measured by HPLC) than between chromaticity values and $\beta$-carotene content (Table 2). This was true for both purée and whole fruit colorimeter measurements.

\section{Discussion}

The objective of this study was to determine whether chromaticity values could be useful for estimating tomato lycopene and $\beta$-carotene contents to an acceptable degree of accuracy. Previous studies had compared chromaticity values of tomato fruit, taken during different ripening stages, to lycopene content as determined by HPLC (Arias et al., 2000) or spectrophotometric measurements of fruit extract (D'Souza et al., 1992). While excellent models were developed for individual cultivars in these studies, the use of only one (Arias et al., 2000) or three cultivars (D'Souza et al., 1992) and the inclusion of unripe, green tomatoes limit the scope and the applicability of the proposed models to a broad range of cultivars or for estimating lycopene content of mature ripe tomato fruits.

Based on the evaluation of 24 tomato genotypes in two harvests, the present study indicated that, if a nondestructive method of estimating carotenoid content is desired, a model based on the chromaticity ratio $\left(\mathrm{a}^{*} / \mathrm{b}^{*}\right)^{2.5}$, that is, Lycopene $=-0.4+53.5$ $\left(\mathrm{a}^{*} / \mathrm{b}^{*}\right)^{2.5}$, would yield a good fit $\left(R^{2}=74 \%\right)$ with actual lycopene content as measured by HPLC (Fig. 1b). The model proposed by D'Souza et al. (1992), that is, Lycopene $=5.6+71.2\left(\mathrm{a}^{*} / \mathrm{b}^{*}\right)^{2}$, was also shown to be applicable to the set of genotypes used in the present study, although it tended to consistently overestimate lycopene content. It is noteworthy that when lycopene measurements from the first harvest were regressed against the same whole fruit chromaticity parameter $\left(\mathrm{a}^{*} / \mathrm{b}^{*}\right)^{2}$ used by $\mathrm{D}^{\prime}$ Souza et al. (1992), the regression coefficients were nearly identical. Although the model by D'Souza et al. (1992) overestimated the lycopene content by $\approx 34 \mu \mathrm{g} \cdot \mathrm{g}^{-1} \mathrm{FW}$, the slope of the line (b $=71.2)$ was similar to the slope in our study $(b=71.7)$ for the same chromaticity parameter $\left[\left(\mathrm{a}^{*} / \mathrm{b}^{*}\right)^{2}\right]$. This implies that, when using whole fruit color measurements, the estimates based on $\left(\mathrm{a}^{*} / \mathrm{b}^{*}\right)^{2}$ or $\left(\mathrm{a}^{*} / \mathrm{b}^{*}\right)^{2.5}$ values may be applied either for comparison of different genotypes or for comparison of fruits from a single cultivar at different stages of ripeness. Such models, however, exhibit only moderate $R^{2}$ values for estimating fruit lycopene concentration (Table 2), mainly because fruit external color does not fully represent the fruit lycopene concentration.

If a destructive method of carotenoid estimation is acceptable, however, estimating lycopene content from purée $\mathrm{a}^{* 4}$ values, that is, Lycopene $=5.8+3.735 \times 10^{-5} \mathrm{a}^{* 4}$, results in a significant increase in accuracy compared with whole fruit estimation while it offers substantial time saving compared with lycopene measurement by HPLC (Fig. 1a). Furthermore, this method of estimation is as accurate as the spectrophotometric measurements presented by Rao et al. (1998), while it is much simpler and no chemical extraction is needed. The model based on the transformed chromaticity value $\mathrm{a}^{* 4}$ explained more than $90 \%$ of the variation in fruit lycopene content as measured by HPLC, whereas the additional time required to take colorimeter measurements of purée, which had already been prepared for other measurements (e.g., pH and soluble solids), amounted to $<2$ min per sample. In comparison, HPLC analysis of tomato carotenoids required a minimum of 30 min of preparation per sample. Also, the colorimeter measurements required no use of toxic chemicals or highly trained labor. Therefore, when screening tomato germplasm or large breeding populations, breeders could easily substitute colorimeter measurements applied to tomato purée for lycopene measurements by HPLC. However, it should be pointed out that the chromaticity values and the proposed regression models cannot entirely substitute for HPLC measurements for determining the precise concentration of fruit lycopene, when such precision is needed.

A critical difference between the colorimetric values measured based on purée reflectance and those measured based on skin (whole fruit) reflectance is that purée reflectance values are minimally affected by skin color. When only one or a few tomato cultivars with the same skin color are used to establish a relationship between skin colorimetric readings and lycopene content, as was done in the studies by D'Souza et al. (1992) and Arias et al. (2000), the effect of skin color variation is ignored. In a red tomato, the fruit skin color can be clear, yellow-orange, or red, all of these cases were represented in our study. Therefore, depending on tomato genotypes used, estimation of fruit lycopene content by measuring chromaticity values of whole fruit can be misleading.

The purée model derived in this study based on the relationship between chromaticity $\mathrm{a}^{* 4}$ values and lycopene measurements by HPLC would be more applicable, and would provide more accurate estimation of fruit lycopene content, than the "purée absorbance method" proposed by Davis et al (2003), which was based on spectrophotometric quantification of lycopene. This is particularly true when dealing with germplasm with varying concentrations of other carotenoids, especially $\beta$-carotene. Without separating individual carotenoids on a chromatographic column, spectrophotometric absorbance values for any carotenoid would be confounded by absorbance due to other carotenoids that are present. Various studies have reported that spectrophotometric methods generally overestimate fruit lycopene content with varying degrees, depending on the genetic backgrounds and carotenoid compositions of the samples (Fish et al., 2002; Lime et al., 1957; Rao et al., 1998). For example, a comparison of the absorbance values of chromatographically separated carotenoids versus those that were not separated prior to spectrophotometry demonstrated that lycopene could be overestimated by up to $26 \%$ in non-chromatographed samples from grapefruit (Lime et al., 1957). In comparison, the purée model proposed here not only is rapid and accurate, but also it could be applied to genotypes with varying concentrations of lycopene and $\beta$-carotene.

Inspection of the different chromaticity values and regression models in the present study suggested that colorimeter readings may not be highly useful for estimating $\beta$-carotene content in tomato fruit. This might be due to the low concentration and limited variation in $\beta$-carotene content across the tomato genotypes examined. Inclusion of a larger number of genotypes and extending the range of fruit $\beta$-carotene content may help developing better models, which can be more useful for estimating this important carotenoid in tomato.

The utility of colorimeter measurements may, however, extend 
beyond estimating carotenoids contents. Both lycopene and soluble solids contents increase during ripening and lycopene content peaks at the intense red ripe stage. The $a^{*} / b^{*}$ and $\left(a^{*} / b^{*}\right)^{2}$ values have been shown to be associated with stages of maturity (Arias et al., 2000) and chromaticity values have been shown to be better indicators of physiological maturity than days after anthesis (Young et al., 1993). For example, the chromaticity a* value from purée had a linear relationship with most fruit constituents analyzed by Young et al. (1993), so harvesting fruit to maximize lycopene would coincide with maximizing other fruit quality components. Also, harvesting fruit when $\mathrm{a}^{*} / \mathrm{b} *$ measurements have plateaued may reduce variations in maturity, eliminating this as a source of non-genetic variation.

\section{Literature Cited}

Arias, R., T.C. Lee, L. Logendra, and H. Janes. 2000. Correlation of lycopene measured by HPLC with the $\mathrm{L}^{*}, \mathrm{a}^{*}, \mathrm{~b}^{*}$ color readings of a hydroponic tomato and the relationship of maturity with color and lycopene content. J. Agr. Food Chem. 48:1697-1702.

Beecher, G.R. 1998. Nutrient content of tomatoes and tomato products. Proc. Soc. Exp. Biol. Med. 218:98-100.

Bertram, J.S. and L.X. Zhang. 1994. Assays for regulation of gap junctional communication and connexin expression by carotenoids. Meth. Enzymol. 234:235-244.

Britton, G., S. Liaaen-Jensen, and H. Pfander. 1995. Carotenoids: Vol. 1B. Spectroscopy. ed. Birkhauser Verlag, Boston, Mass.

Chen, F.Q., M.R. Foolad, J. Hyman, D.A. St. Clair, and R.B. Beelman. 1999. Mapping of QTLs for lycopene and other fruit traits in a Lycopersicon esculentum $\mathrm{x}$ L-pimpinellifolium cross and comparison of QTLs across tomato species. Mol. Breeding 5:283-299.

Chug-Ahuja, J.K., J.M. Holden, M.R. Forman, A.R. Mangels, G.R. Beecher, and E. Lanza. 1993. The development and application of a carotenoid database for fruits, vegetable, and selected multicomponent foods. J. Amer. Diet. Assoc. 93:318-323.

D’Souza, M.C., S. Singha, and M. Ingle. 1992. Lycopene concentration of tomato fruit can be estimated from chromaticity values. HortScience 27:465-466.

Davis, A.R., W.W. Fish, and P. Perkins-Veazie. 2003. A rapid spectrophotometer method for analyzing lycopne conten in tomato and tomato products. Postharvest Biol. Technol. 28:425-430.

Di Mascio, P., T.P. Devasagayam, S. Kaiser, and H. Sies. 1990. Carotenoids, tocopherols and thiols as biological singlet molecular oxygen quenchers. Bioch. Soc. Trans. 18:1054-1056.

Emenhiser, C., L.C. Sander, and S.J. Schwartz. 1995. Capability of a polymeric C30 stationary phase to resolve cis-trans carotenoid isomers in reversed-phase liquid chromatography. J. Chromatogr. 707:205-216.

Epler, K.S., L.C. Sander, R.G. Ziegler, S.A. Wise, and N.E. Craft. 1992. Evaluation of reversed-phase liquid chromatographic columns for recovery and selectivity of selected carotenoids. J. Chromatogr. 595:89-101.

Fish, W.W., P. Perkins-Veazie, and J.K. Collins. 2002. A Quantitative assay for lycopene that utilizes reduced volumes of organic solvents. J. Food Compos. Anal. 15:309-317.

Fuhramn, B., A. Elis, and M. Aviram. 1997. Hypocholesterolemic effect of lycopene and $\beta$-carotene is related to suppression of cholesterol synthesis and augmentation of LDL receptor activity in macrophage. Biochem. Biophys. Res. Comm. 233:658-662.

Gartner, C., W. Stahl, and H. Sies. 1997. Lycopene is more bioavailable from tomato paste than from fresh tomatoes. Amer. J. Clinic. Nutri. $66: 116-122$.
Gerster, H. 1997. The potential role of lycopene for human health. J. Amer. Coll. Nutri. 16:109-126.

Giovannucci, E. 1999. Tomatoes, tomato-based products, lycopene, and cancer; Review of the epidemiologic literature. J. Natl. Cancer Inst. 91:317-331.

Hart, D.J. and K.J. Scott. 1995. Development and evaluation of an HPLC method for the analysis of carotenoids in foods, and the measurement of the carotenoid content of vegetables and fruits commonly consumed in the UK. Food Chemist. 54:101-111.

Hunter, R.S. and R.W. Harold. 1987. The measurement of appearance. 2nd ed. Wiley, New York.

Kamber, M. and H. Pfander. 1984. Separation of carotenoids by highperformance liquid chromatography. III. 1,2-epoxycarotenoids [relevant to food analysis]. J. Chromatogr. 295:295-298.

Kimura, M. and D.B. Rodriguez-Amaya. 1999. Sources of errors in the quantitative analysis of food carotenoids by HPLC. Arch. Latinoam. Nutr. 49:58S-66S.

Kohlmeier, L., J.D. Kark, E. Gomez-Gracia, B.C. Martin, S.E. Stec, A.F. Kardinaal, J. Ringstad, M. Thamm, V. Masaev, R. Riemersma, J.M. Martin-Moreno, J.K. Huttunen, and F.J. Kok. 1997. Lycopene and myocardial infarction risk in the EURAMIC Study. Amer. J. Epidemiol. 146:618-626.

Krinsky, N.I. 1998. Overview of lycopene, carotenoids, and disease prevention. Proc. Soc. Expt. Biol. Med. 218:95-97.

Levy, J., E. Bosin, B. Feldman, Y. Giat, A. Miinster, M. Danilenko, and Y. Sharoni. 1995. Lycopene is a more potent inhibitor of human cancer cell proliferation than either alpha-carotene or beta-carotene. Nutr. Cancer 24:257-266.

Lime, B.J., F.P. Griffiths, R.T. O'Connor, D.C. Heinzelman, and E.R. McCall. 1957. Spectrophotometric methods for determining pigmentation - beta-carotene and lycopene - in ruby red grapefruit. Agr. Food Chemist. 5:941-944.

Rao, A.V. and S. Agarwal. 1998. Bioavailabililty and in vivo antioxidant properties of lycopene from tomato products and their possible role in prevention of cancer. Nutr. Cancer 31:199-203.

Rao, A.V., Z. Waseem, and S. Agarwal. 1998. Lycopene content of tomatoes and tomato products and their contribution to dietary lycopene. Food Res. Intl. 31:737-741.

Sadler, G., J. Davis, and D. Dezman. 1990. Rapid extraction of lycopene and $\beta$-carotene from reconstituted tomato paste and pink grapefruit homogenates. J. Food Sci. 55:1460-1461.

Scott, K.J. 1992. Observations on some of the problems associated with the analysis of carotenoids in foods by HPLC. Food Chemist. 45:357-364.

Scott, K.J., P.M. Finglas, R. Seale, D.J. Hart, and I.d. Froidmont-Gortz. 1996. Interlaboratory studies of HPLC procedures for the analysis of carotenoids in foods. Food Chemist. 57:85-90.

Sies, H. and W. Stahl. 1998. Lycopene: Antioxidant and biological effects and its bioavailability in the human. Proc. Soc. Expt. Biol. Med. 218:121-124.

Stahl, W. and H. Sies. 1996. Lycopene: A biologically important carotenoid for humans? Arch. Biochem. Biophys. 336:1-9.

Young, T.E., J.A. Juvik, and J.G. Sullivan. 1993. Accumulation of the components of total solids in ripening fruits of tomato. J Amer. Soc. Hort. Sci. 118:286-292.

Zhang, L.X., R.V. Cooney, and J.S. Bertram. 1991. Carotenoids enhance gap junctional communication and inhibit lipid peroxidation on $\mathrm{C} 3 \mathrm{H} / 10 \mathrm{~T} 1 / 2$ cells: Relationship to their cancer chemopreventive action. Carcinogenesis 12:2109-2114.

Zhang, L.X., R.V. Cooney, J.S. Bertram, and G. Wolf. 1993. Carotenoids up-regulate connexin 43 gene expression independent of their provitamin A or antioxidant properties. Amer. J. Clinic. Nutr. 58:115-117. 